\title{
Mapping and the Spatial Analysis of Disability in the Khuzestan Province, Iran
}

\author{
${ }^{1}$ Mohammad Taghi Razavian, ${ }^{2}$ Zohre Fanni, ${ }^{3}$ Jamileh Tavakolinia, ${ }^{4}$ Alireza Mohammadi, ${ }^{5}$ Elahe \\ Pishgar \\ 1,2,3,4,5 Department of Geography, Faculty of Humanities, University of Mohaghegh \\ Ardabili, Ardabil, Iran
}

\begin{abstract}
This study aims to mapping and spatial analyzing of disability in the Khuzestan Province, Iran by using Geographic Information System. A total of 82, 674 disabled people information were included in the study. The 40 informational fields have been classified into 11 main categories. The Geographically Weighted Regression (GWR) technique were used for mapping and discovering the relationships. The results show that, $68.87 \%$ of the disabled people were urban residents. The disability rate of cities ranges from 10.54 to 43.05 . As many as $63.43 \%$ of the disabled suffered from severe and extremely severe disabilities. About $60.59 \%$ of disabled were males $65.17 \%$ were married. In terms of educational level, as many as $87.61 \%$ of them had educational levels lower than junior high school. In terms of occupational status, about $74.24 \%$ of them were unemployed. There was a positive relationship between poverty and disability rate in $70.37 \%$ of the counties. Moreover, there was a positive relationship between population and disability ratio. In terms of disability variables, a significant difference was observed between different counties. The output of GWR method indicates that there was a positive and significant relationship between population and poverty level with disability ratio (Std. Dev. $\geq 0.05$ ). However, the severity of this relationship varies in different counties.
\end{abstract}

Keywords: Disability, Geographically Weighted Regression, Geographic Information System

\section{Introduction}

From the 80-million population of Iran, nearly $1,450,000$ people (1.81) suffer from one kind of disability [1]. The distribution of the disabled individuals is not homogenous in different parts of Iran. However, the facilities and resources have not been equally distributed for the needs of the disabled [2]. Although disability is one of the obstacles of development in Iran, it has not been analyzed by spatial approaches and methods. There is little information on the status of provinces especially the border ones and those involved in Iran-Iraq War (1980-1988). Most of the plans related to the disabled individuals focus on "sectoral policies", and the geographical aspects have been given little attention in the planning. Investigating the issue of disability in its geographical background helps researchers have a better understanding of the issue and its unique features [3].

* Corresponding author:

Published online at http://IJDS.ub.ac.id/2019

Copyright (C) 2019PSLD UB Publishing. All Rights Reserved
Mapping and spatial reflection of disability status help the specialists and policymakers of health and treatment allocate the resources and facilities in an optimal way and provide preventive medical programs appropriate for the status of different regions. In the studies conducted on disability, the spatial aspect has been given little attention, and it has been dealt with only in recent decades.

In a study conducted by Moss et al [4], the spatial analyses have been used for investigating the disability indices in the United States. They concluded that there is significant difference between different areas in terms of disability variables. Goli et al [2] have investigated the spatial status of mental disability in Iran. They concluded that the investigating the disability status in its geographical background helps policymakers adopt better policies in health and treatment sector. Zheng et al [5] have investigated neck disability by applying statistical methods. 


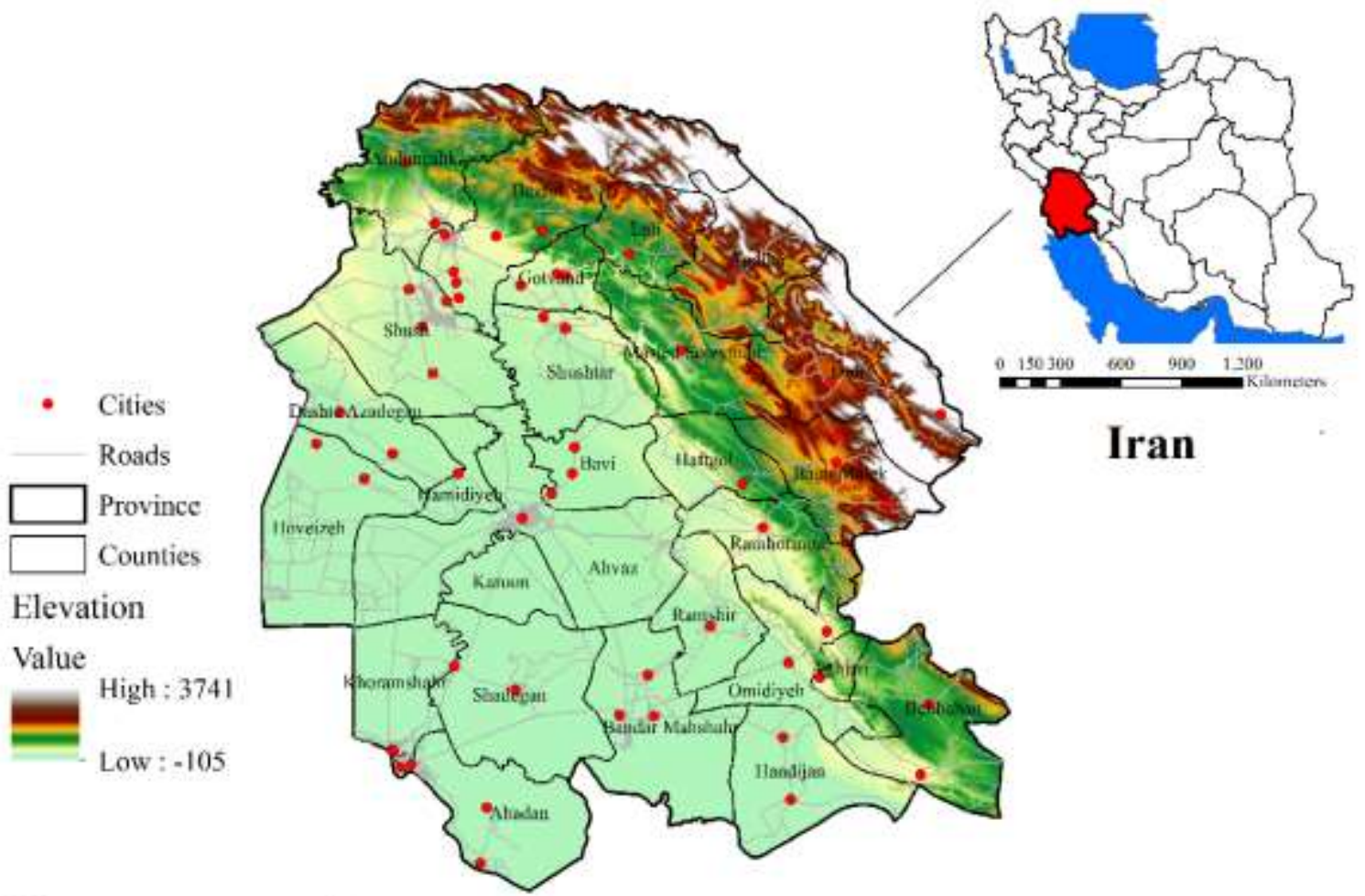

Khuzestan province

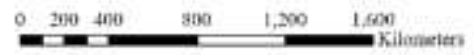

Fig 1. Map of study area (Khuzestan Province)

However, they have mostly dealt with the statistical studies and have ignored the geographical aspects. In his study, Islam [6] deals with the analysis of patterns and spatial relationships of disability in West Bengal. Islam has concluded that there is a significant difference between different areas in terms of spatial distribution, the disabled individuals' being urban-residents and rural residents, and their gender. The main purpose of this study is to mapping and analyzing of disability through using Geographic Information System (GIS). Secondary purposes of the study include:

- Understanding the residential statues patterns of the disabled individuals;

- Understanding the inter-regional differences in terms of disability rate

- Identifying the severity of disability within counties;

- Understanding differences between counties in terms of social characteristics of disabled individual;

- Investigating the relationship between disability rate and population density;
- Investigating the relationship between disability rate and poverty level of the counties;

The rest of this study deals with four main parts including materials and methods, findings, discussion, and conclusions.

\section{Method}

\subsection{The study area}

Khuzestan province is $64,055 \mathrm{~km}^{2}$ located in the geographical coordinates of $31.4360^{\circ} \mathrm{N}$ and $49.0413^{\circ} \mathrm{E}$ in northwestern Iran at the border of Iraq. This province has a population of 4,710, 506 people (2016 census) $72 \%$ of whom are urban- residents. This province deals with the disability of its population for various reasons including genetic problems, environmental problems, accidents, and IranIraq War (1980-1988) [7]. For example, only in the years 2011-2016, approximately 5,685 individuals were either killed or disabled as a result of vehicle accidents [8]. This province is divided into 27 counties, 76 cities, and 4,042 villages. Khuzestan is one of the border provinces of Iran that was greatly affected by 
Iran-Iraq War, and a large population of disabled individuals live in this province. The statistics of the disabled individuals have been registered for each city.

\subsection{Data and spatial geodatabase}

The statistical population of the present study includes 82,674 disabled individuals of Khuzestan province. The information of the statistical population was obtained from Welfare Organization of Khuzestan Province [7]. The raw statistical data have been

Table 1: The list of variables and fields used for mapping in GIS

\begin{tabular}{|c|c|}
\hline Category & Sub category (Variables) \\
\hline Type of disability & $\begin{array}{l}\text { X1: visual; X2: Physical and mobility; X3: intellectual; X4: mental; X5: Auditory; } \\
\text { X6: voice and speech }\end{array}$ \\
\hline Severity of disability & X7: very severe; X8: severe; X9: moderate; X10: minor; X11: not specified \\
\hline Educational level & $\begin{array}{l}\text { X12: illiterate; X13: Islamic seminaries degrees; X14: elementary and junior high } \\
\text { school; X15: high school diploma; X16: associate degree; X17: BA/BS; X18: } \\
\text { MA/MS; X19: Ph.D. }\end{array}$ \\
\hline County of residence & $\mathrm{X} 20$ : Name of the county \\
\hline Kind of residential place & X21: rural residents; X22: urban residents; X23: nomads \\
\hline Age group & $\mathrm{X} 24:$ mean age \\
\hline Marital status & $\begin{array}{l}\text { X25: married; X26: single; X27: estranged; X28: divorced; X29: widowed; X30: not } \\
\text { specified }\end{array}$ \\
\hline Gender & X31: male; X32: female; X33: bi-gender \\
\hline Employment status & $\begin{array}{l}\text { X34: employed; X35: unemployed; X36: retired; X37: physically unable to work; } \\
\text { X38: other }\end{array}$ \\
\hline Population of the county & X39: population of the county \\
\hline $\begin{array}{l}\text { Employment status of the } \\
\text { county }\end{array}$ & X40: developed, less developed, partially-developed, completely deprived \\
\hline
\end{tabular}

For conducting the analyses, the raw data were first coded in Excel (Microsoft corporation software). In the next step, the frequency and percentage of each variable were measured. Then the files of the maps having geographical coordinates were obtained from Administration of Roads and Urban Development. Then, the categorized data of the variables were joined to the descriptive table of the map of the counties in ArcGIS edition 10.6 (ESRI designed), and a Geodatabase was created for conducting analyses.

\subsection{Techniques}

The methods used in the present study are of two types. The first type has to do with descriptive methods, and the second type has to do with correlation analysis methods. As for the first type (descriptive), descriptive tables were used in EXCEL. For extracting the disability maps, ArcGIS was used. In ArcGIS, Quantities and Graduate Colors method was used in Symbology for classifying and registered from the year 2005 until the beginning of 2018. The main variables used in this study are 11 categories including the type of disability, the severity of disability, educational level of the disabled individuals, county of residence, the kind of residential place, age, marital status, gender, employment status, population of the county, and the development status of the counties. Table 1 indicates the variables used in this research and their codes in GIS. 
estimate for variable $\mathrm{k}, \mathrm{X}_{\mathrm{ik}}$ is the value of the $\mathrm{k}^{\text {th }}$ variable for $\mathrm{i}$, and $\varepsilon_{\mathrm{i}}$ is the error term. The GWR generates a separate regression equation for each observation. Each equation is calibrated using a different weighting of the observations contained in the dataset [10]. In this study, GWR method in ArcGIS, used to calculate relationships between disability (dependent variable) and research exploratory parameters such as population.

\section{Results}

\subsection{Residential status}

Table 2 indicates the residential status of the disabled individuals in Khuzestan. From among the total 82,674 disabled individuals, as many as 58,489 of them $(68.87 \%)$ were urbanresidents, $23,144 \quad(31.06 \%)$ were ruralresidents, and 41 individuals $(0.07 \%)$ were nomads. Ahvaz, as the capital of the province, has the highest frequency disabled people with 16,502 disabled individuals (21.25\%). Except of Shadegan and Lali, Baghmalek, and Andika, the disabled individuals were frequently urbanresidents. Most of the disabled nomads reside in Ramhormoz Andika (0.69\%), Dezful (0.17), Gotvand (0.45\%), and Ramhormoz (0.20).

As it can be seen in table 2, since Ahvaz has the largest population, it has a higher number of disabled individuals. Thus, in the present study, the comparison of disability indices of each county has been conducted based on the population of the disabled individuals of that county. The last column of table 2 indicates the population distribution of each county and the ratio of disable people (disabled person per 1,000 people) in each county. This table indicates that the following counties are facing the highest disability rates in comparison to their populations: Haftgol (43 per 1,000); Andika (34 per 1,000); Baghmalek (38 per 1,000); and Shadegan (31 per 1,000).

\subsection{Type of disability}

Data analysis indicates that from among the entire population of the disabled individuals of the province, as many as 35,079 $(42.43 \%)$ suffer from physical disability (Figure 2A), 22, 015 individuals (26.63\%) suffered from intellectual disability (Figure 2B), 10.049 individuals (12.21\%) suffered from visual disability (Figure 2C), 9,635 individuals (11.65\%) suffered from auditory disability (Figure 2D), 5,726 individuals

Cite this as:

Razavian, Mohammad Taghi et al, 2019. Mapping and the Spatial Analysis of Disability in the Khuzestan Provinve, Iran. Indonesian Journal of Disability Studies (IJDS).2019: Vol. 6(1): PP 102-112.
$(6.93 \%)$ suffered from mental disability (Figure 2E), and 125 individuals (0.15\%) suffered from speech disability (Figure $2 \mathrm{~F}$ ). As Figure 2 indicates, in terms of the ratio of each county from the entire population of physical disability cases, Baghmalek (61\%), Ramhormoz (58\%), Lali (47\%), Haftgol (47\%), and Hoveizeh (47\%) had the highest frequency of physical disability. Intellectual disability had the highest frequency in Aghajari (37\%), Abadan (33\%), Dashte Azadegan (31\%), Hoveizeh (31\%), and Karoon $(31 \%)$ respectively. Visual disability was most frequently observed in Hendijan (23\%), Shush (18\%), Andika (17\%), and Shadegan (17\%) respectively. Mental disability had the highest frequency in Masjed Soleyman (12\%), Andimeshk (11\%), Dezful (11\%), Andika (10\%), and Bavi (10\%) respectively. Auditory disability was most frequently seen in Karoon (16\%), Hamidiyeh $(15 \%)$, and Shushtar $(15 \%)$. Speech disability has been observed in Behbahan (1\%), Hoveizeh (1\%), and Hendijan (1\%), and it is not very significant in other counties.

\subsection{The severity of disability}

The data analysis indicates that from among the entire population of the disabled individuals of Khuzestan, as many as 7,119 individuals $(8.61 \%)$ suffer from minor disability (Figure 3A), 13,192 individuals $(15.96 \%)$ suffer from moderate disability (Figure 3B), 40,430 individuals (48.90\%) suffer from severe disability (Figure 3C), and 21,933 individuals $(26.53 \%)$ suffer from very severe disability. Although $70 \%$ of the counties are dealing with severe and very severe disabilities, as it can be observed in Figure 3, severe and very severe disability have the highest frequency in Hoveizeh (81.2\%), Dashte Azadegan (78.15\%), Aghajari (77.94\%), Omidiyeh (78.04\%), Izeh (78.87\%), Andimeshk (71.69\%), Masjed Soleyman (70.59), and Gotvand (70.50\%).

\subsection{Gender and age status}

The investigation of the data indicates that age distribution of the entire population of the disabled individuals of Khuzestan is as follows: 2,423 individuals $(2.93 \%)$ were in the age group of 0-6 years old; 10,033 individuals $(12.14 \%)$ were in the age group of 7-15 years 105 
old; 28,935 individuals (35\%) were in the age group of 16-30 years old; 34,672 individuals $(41.94 \%)$ were in the age group of 31-60 years old; and 6,611 individuals (8\%) were in the age group of over-60 age group. The disability mean age of the entire province is 32 . The maximum mean age is 39 years old; it is for Behbahan. The minimum mean age is 25 years old in Hoveizeh. However, as many as 50.57\% of the entire population of the disabled are in the age groups of less than 30 years old. As many as 32,151 individuals (38.89\%) are females and 50,388 individuals (60.59\%) are males. As many as 135 individuals were bigenders.

Table 2: Khuzestan province disabled population statistics by county, 2018.

\begin{tabular}{|c|c|c|c|c|c|c|c|c|c|c|}
\hline \multirow[t]{2}{*}{ County } & \multirow{2}{*}{$\begin{array}{c}\text { populatio } \\
\mathbf{n}\end{array}$} & \multirow[b]{2}{*}{ Urban } & \multicolumn{8}{|c|}{ Disabled } \\
\hline & & & Rural & Nomad & Total & $\begin{array}{c}\text { Urban } \\
(\%)\end{array}$ & $\begin{array}{c}\text { Rural } \\
(\%)\end{array}$ & $\begin{array}{c}\text { Nomad } \\
(\%)\end{array}$ & $\begin{array}{l}\text { Total } \\
(\%)\end{array}$ & $\begin{array}{c}\text { per } 1000 \\
\text { population }\end{array}$ \\
\hline Abadan & 298,000 & 3,557 & 632 & 0 & 4,189 & 84.91 & 15.09 & 0.00 & 5.07 & 14.06 \\
\hline Aghajari & 17,000 & 263 & 25 & 0 & 288 & 91.32 & 8.68 & 0.00 & 0.35 & 16.94 \\
\hline Ahvaz & $1,300,000$ & 16,502 & 1,070 & 0 & 17,572 & 93.91 & 6.09 & 0.00 & 21.25 & 13.52 \\
\hline Andika & 47,000 & 109 & 1,463 & 11 & 1,583 & 6.89 & 92.42 & 0.69 & 1.91 & 33.68 \\
\hline Andimeshk & 171,000 & 2,425 & 685 & 2 & 3,112 & 77.92 & 22.01 & 0.06 & 3.76 & 18.20 \\
\hline Baghmalek & 105,000 & 1,621 & 2,353 & 0 & 3,974 & 40.79 & 59.21 & 0.00 & 4.81 & 37.85 \\
\hline $\begin{array}{l}\text { Bandar } \\
\text { Mahshahr }\end{array}$ & 296,000 & 2,931 & 188 & 0 & 3,119 & 93.97 & 6.03 & 0.00 & 3.77 & 10.54 \\
\hline Bavi & 96,000 & 1,356 & 449 & 0 & 1,805 & 75.12 & 24.88 & 0.00 & 2.18 & 18.80 \\
\hline Behbahan & 180,000 & 1,980 & 1,352 & 0 & 3,332 & 59.42 & 40.58 & 0.00 & 4.03 & 18.51 \\
\hline $\begin{array}{l}\text { Dashte } \\
\text { Azadegan }\end{array}$ & 107,000 & 1,223 & 643 & 0 & 1,866 & 65.54 & 34.46 & 0.00 & 2.26 & 17.44 \\
\hline Dezful & 443,000 & 3,890 & 1,443 & 9 & 5,342 & 72.82 & 27.01 & 0.17 & 6.46 & 12.06 \\
\hline Gotvand & 65,000 & 863 & 455 & 6 & 1,324 & 65.18 & 34.37 & 0.45 & 1.60 & 20.37 \\
\hline Haftgol & 22,000 & 775 & 172 & 0 & 947 & 81.84 & 18.16 & 0.00 & 1.15 & 43.05 \\
\hline Hamidiyeh & 53,000 & 763 & 45 & 0 & 808 & 94.43 & 5.57 & 0.00 & 0.98 & 15.25 \\
\hline Hendijan & 38,000 & 740 & 241 & 0 & 981 & 75.43 & 24.57 & 0.00 & 1.19 & 25.82 \\
\hline Hoveizeh & 38,000 & 432 & 118 & 0 & 550 & 78.55 & 21.45 & 0.00 & 0.67 & 14.47 \\
\hline Izeh & 198,000 & 3,402 & 1,536 & 0 & 4,938 & 68.89 & 31.11 & 0.00 & 5.97 & 24.94 \\
\hline Karoon & 105,000 & 1,441 & 1,000 & 0 & 2,441 & 59.03 & 40.97 & 0.00 & 2.95 & 23.25 \\
\hline $\begin{array}{l}\text { Khoramsha } \\
\text { hr }\end{array}$ & 170,000 & 1,943 & 661 & 0 & 2,604 & 74.62 & 25.38 & 0.00 & 3.15 & 15.32 \\
\hline Lali & 37,000 & 432 & 436 & 3 & 871 & 49.60 & 50.06 & 0.34 & 1.05 & 23.54 \\
\hline $\begin{array}{l}\text { Masjed } \\
\text { Soleyman }\end{array}$ & 113,000 & 2,408 & 272 & 0 & 2,680 & 89.85 & 10.15 & 0.00 & 3.24 & 23.72 \\
\hline Omidiyeh & 92,000 & 1,269 & 393 & 0 & 1,662 & 76.35 & 23.65 & 0.00 & 2.01 & 18.07 \\
\hline Ramhormoz & 113,000 & 2,021 & 994 & 6 & 3,021 & 66.90 & 32.90 & 0.20 & 3.65 & 26.73 \\
\hline Ramshir & 54,000 & 872 & 540 & 0 & 1,412 & 61.76 & 38.24 & 0.00 & 1.71 & 26.15 \\
\hline Shadegan & 138,000 & 1,661 & 2,617 & 0 & 4,278 & 38.83 & 61.17 & 0.00 & 5.17 & 31.00 \\
\hline Shush & 205,000 & 2,317 & 1,683 & 3 & 4,003 & 57.88 & 42.04 & 0.07 & 4.84 & 19.53 \\
\hline Shushtar & 192,000 & 2,293 & 1,678 & 1 & 3,972 & 57.73 & 42.25 & 0.03 & 4.80 & 20.69 \\
\hline $\begin{array}{l}\text { Total/Avera } \\
\text { ge }\end{array}$ & $4,693,000$ & 59,489 & $\begin{array}{l}23 \\
144\end{array}$ & 41 & 82,674 & 68.87 & 31.06 & 0.07 & 100 & 22 \\
\hline
\end{tabular}


a

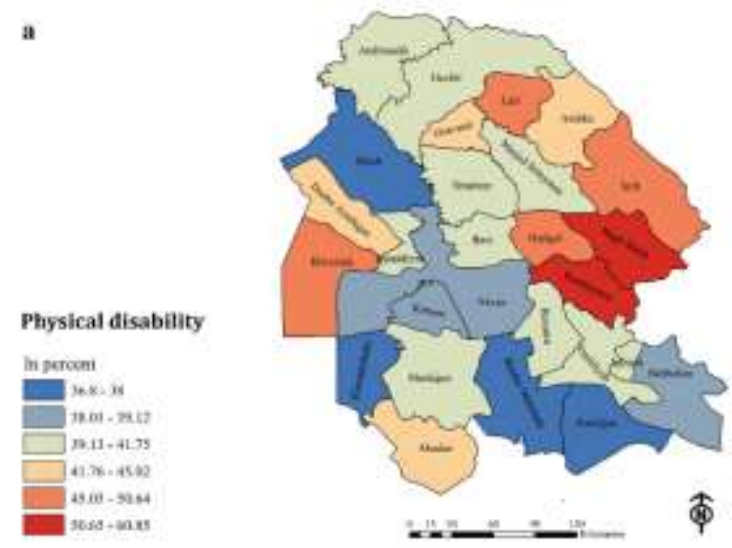

c

Seeing desability

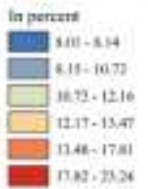

e

Mental disability in perces:

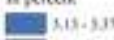

- $138-4+4$

$4.71-42$

Tesing

Tiso-is

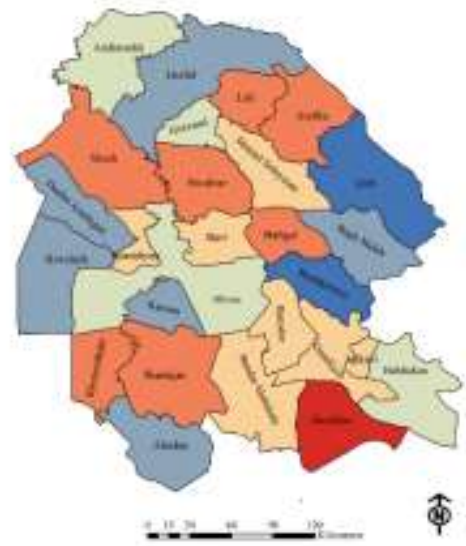

b

Intellectual disability

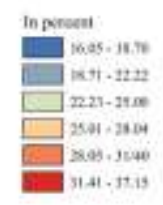

d

Hearing disabitity

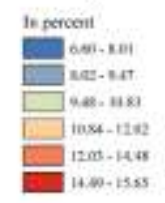

f

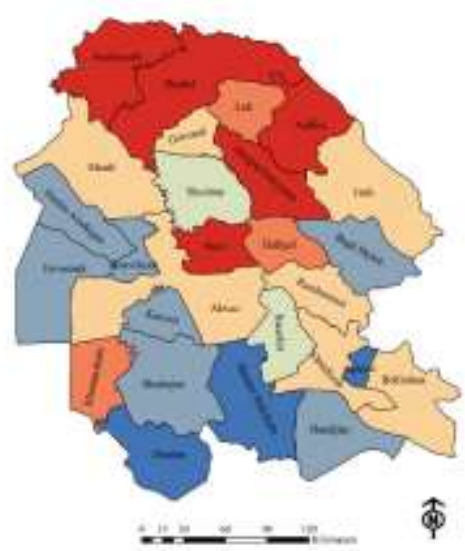

Speech disability

topereat

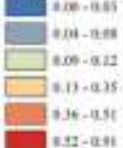

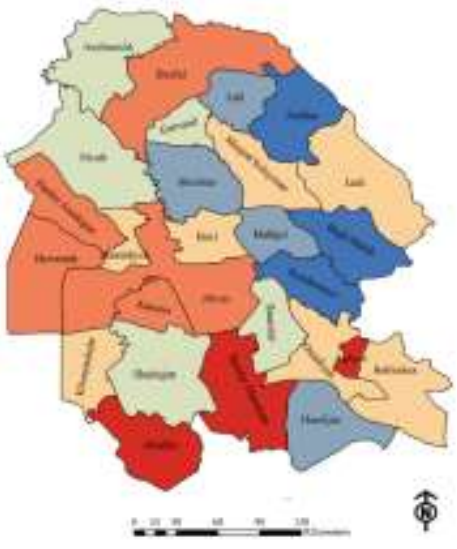

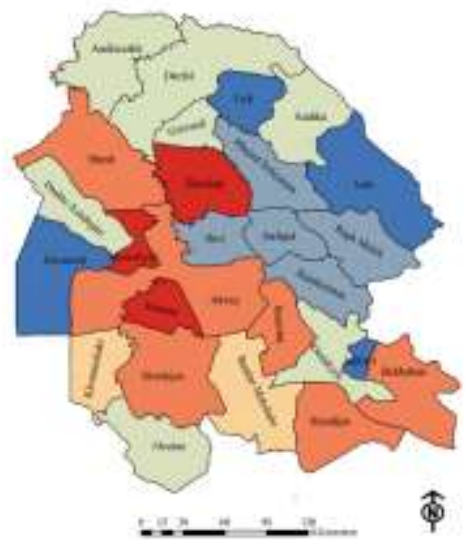

థ

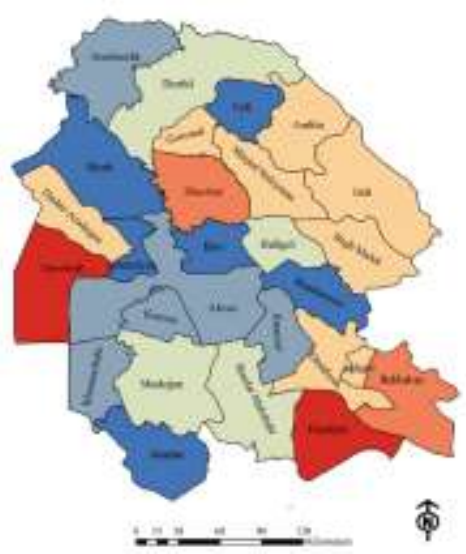

Figure 2. Map of disability ratio by type 


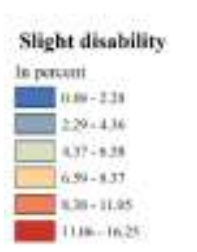

b

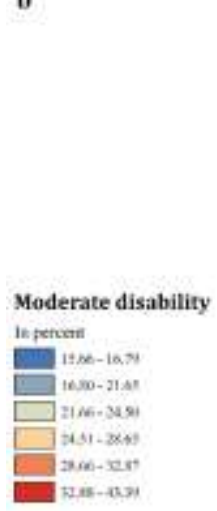

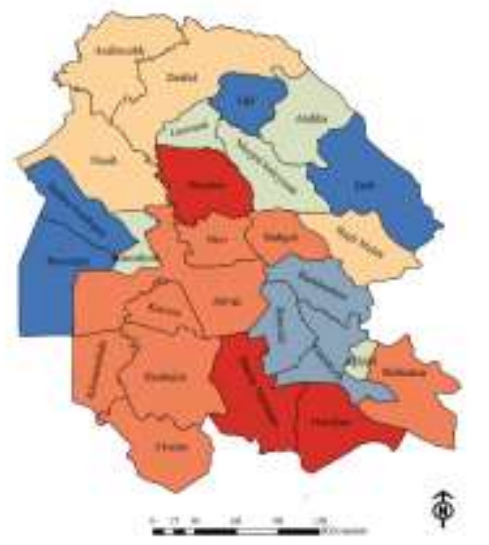

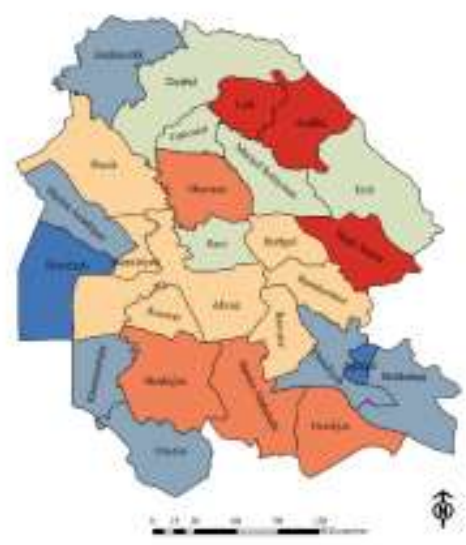

d
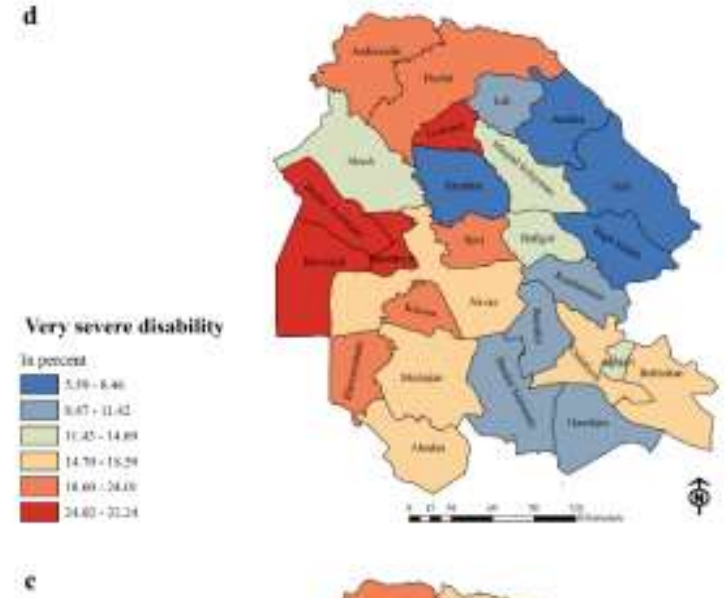

Severe disahility
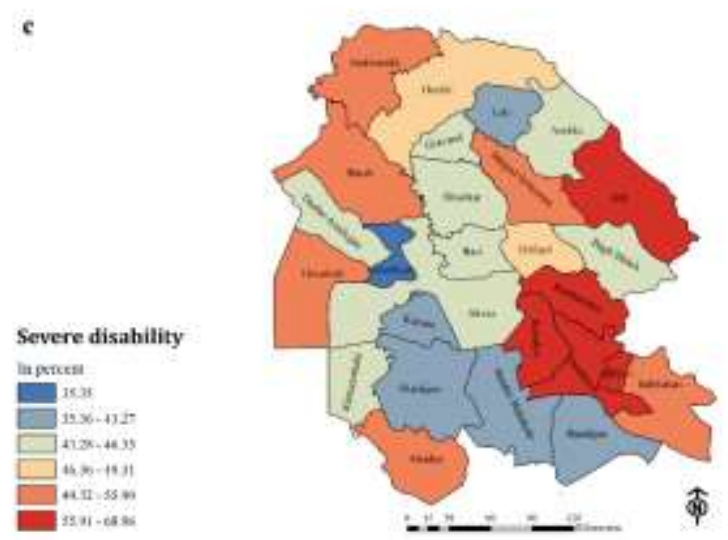

Figure 3. Map of disability severity ratio

\subsection{Marital status}

Data analysis indicates that from the entire population of the disabled individuals, as many as $53,878(65.17 \%)$ disabled individuals are married. Moreover, 28.181 (34.09\%) are single, 235 individuals $(0.28 \%)$ are divorced, 310 individuals $(0.37 \%)$ are widowed, and as many as 70 individuals $(0.08 \%)$ are estranged. In terms of marital status, the counties of Khuzestan are not significantly different. As the Figure 3 indicates, in some counties such as Gotvand, only $34.77 \%$ of the disabled population are married. However, as many as $84.63 \%$ of the disabled population are married in Bavi.

\subsection{Educational level}

The investigation of the data indicates that from among the entire population of the disabled individuals, 39,181 individuals $(47.39 \%)$ are illiterate, 33,254 individuals $(40.22 \%)$ had elementary or junior high school degrees, 5,480 individuals $(6.63 \%)$ had high school diploma, 2,928 individuals (3.54\%) had associated degrees, 399 individuals (0.48) had BA/BS degrees, 1,384 individuals (1.67\%) had MA/MS degrees, 34 individuals $(0.04 \%)$ had $\mathrm{Ph} . \mathrm{D}$. degree, and as many as 15 individuals had degrees from Islamic seminaries. The findings of data analysis indicate that different counties are not significantly different in terms of the educational level. The highest frequency of illiteracy is related to Khoramshahr $(59.55 \%)$, and the lowest frequency of illiteracy is for Ahvaz (39.77\%). In total, as many as $80 \%$ of the total population of the disabled are classified as illiterate individuals or individuals with elementary school or junior high school degrees. As many as $56.7 \%$ of the disabled are men, $43.1 \%$ are women, and $0.2 \%$ are bi-genders. 


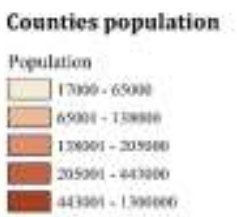

c

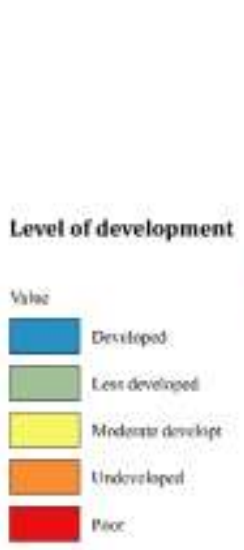

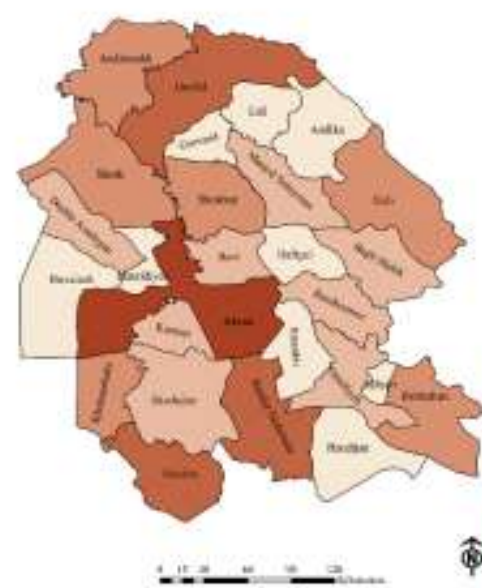

\section{画}

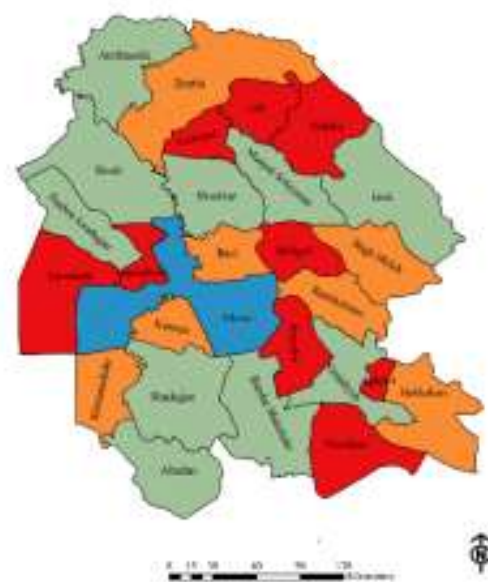

歹 b
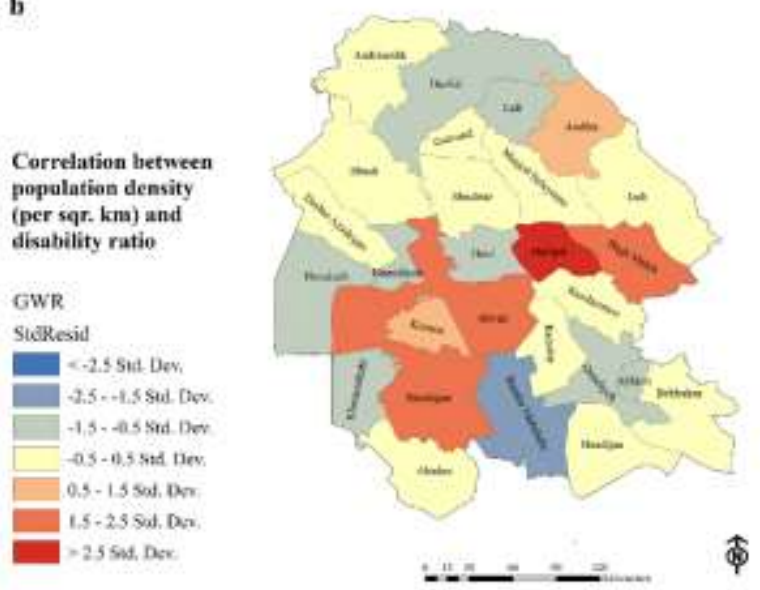

d

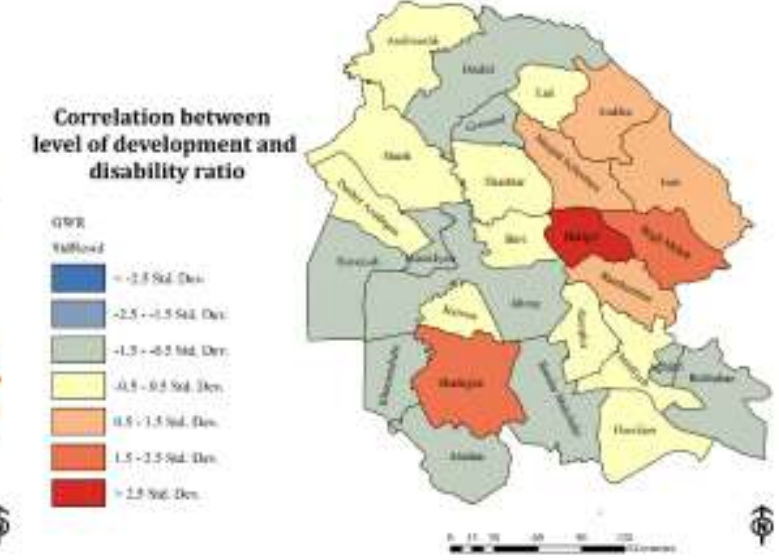

Figure 4. Correlation between disability ratio, population and development degree based on GWR method results

\subsection{Employment status}

Data analysis indicates that as many as 62,725 individuals $(74.24 \%)$ are unemployed, 10.583 individuals $(13.07 \%)$ are physically disabled, 3,837 individuals $(3.83 \%)$ are employed, and 959 individuals $(0.74 \%)$ are retired. As many as 4,570 disabled individuals are not capable of doing anything. More than $10 \%$ of the disabled individuals are employed only in some counties like Haftgol, Dezful, and Hendijan. In total, as many as 78,837 disabled individuals $(96.17 \%)$ have no job or lack the ability to work.

\subsection{The relationship between population and disability}

As it can be seen in table 2, Haftgol has the highest rate of disability with $43.05 \%$, and Mahshahr has the lowest of disability with $10.54 \%$. It is assumed that the increase of population results in an increase in the ratio of the disabled individuals. For testing this hypothesis, GWR method was used. Figure 4 indicates the population of each city and the result of testing this relationship. According to the values of standard deviation observed (Std. Dev.), this relationship is extremely strong and positive in Haftgol with the Std. Dev. Of 2.5 at the significance level of 99\%. In Shadegan, Ahvaz, and Bagh Malek, the Std. Dev. value is 1.5-2.5; the Std. Dev. is positive, and the relationship is strong. In Andika and Hendijan, the Std. Dev. value is 0.5-1.5; the relationship is positive and average. However, in other counties including Karoon, Behbahan, Ramshir, Ramhormoz, Izeh, Masjed Soleyman, Shushtar, Dashte Azadegan, Shush, Gotvand, Lali and Andimeshk, the Std. Dev. value is $-0.5-0.5$ indicating a positive weak relationship. As for other counties, the Std. Dev. value ranges between -0.5 to -2.5 ; this indicates a negative relationship. The result of using this method indicates that from among 27 counties investigated, there was a positive and significant relationship between population 
and disability in 18 counties (67\%). This relationship was extremely severe in 6 counties $(22.2 \%)$.

\subsection{The relationship between poverty and disability}

This has been confirmed that there is a positive and significant relationship between disability and poverty especially in developing countries. Poverty increases the likelihood of suffering from disabilities, and disability results in poverty as well $[11,12]$. Recent studies indicate that Khuzestan is dealing with poverty and regional imbalance for various reason such as Iran-Iraq War, congestion of population, and inequality in distributing the resources and facilities [13]. Figure 4 indicates the total status of development and poverty of different counties of Khuzestan (it has been extracted from the findings of the study conducted by Maleki \& Ahmadi, [13]. In this study, regional poverty has been considered as the independent variable and disability has been regarded as the dependent variable. For discovering the relationship between these two variables (poverty and disability), GWR has been used, and Figure 4 indicates the result of the test. This relationship is positive and extremely strong in Haftgol with the Std. Dev. value of more than 2.5. In Baghmalek and Shadegan, the Std. Dev. value ranges between 1.5-2.5; the relationship is positive and strong. This relatiobship is positive and average on Ramhormoz, Izeh, Masjed Soleyman, and Andika. As for other counties, this relationship ranges between $>-2.5$ to -0.5 . The findings of using this method indicates that from among 27 counties investigated, there was a positive and significant relationship between poverty and disability in 19 counties. This relationship is severe in three counties $(11.1 \%)$ and strong in 4 counties $(14.8 \%)$.

\section{Discussion}

The findings of the present study indicate that although most of the disabled were urban residents, rural residents and nomads had a significant ratio of the disabled population as well. This is of great significant, as the facilities available for the disabled individuals are limited. The disability rate ranges from 10.54 to 43.05 in different counties, and in terms of disability rate, no significant difference was observed. Most of the disabled individuals are dealing with severe and very severe disabilities (70\%); this brings about numerous challenges for the authorities. The findings of the present study indicate that there are more disabled men than women. It seems that the incidence of Iran-Iraq War, vehicle accidents, and other accidents happening in the individuals' workplace have resulted in an increase of disability in Khuzestan especially among men. As men are in charge of household in most of the Iranian families, men's disability result in psychological and economic losses. Most of the disabled individuals are married, and some of them have gone disabled after marriage. This affects not only the disable individuals but also their families.

The illiteracy ratio of the disabled individuals is high in most of the counties. This means that most of the counties have failed to provide proper opportunities for training the disabled people. Most of the disabled individuals are not able to start a business; this means that that they are more dependent on state supports. The findings indicate that there is significant relationship between population and disability in only a few counties. This means that population and genetics are not the only factors of the increased rate of disability, and other environmental factors (War, accidents, etc.) are involved in the increased or decreased rate of disability. Moreover, the findings also indicate that there is an extremely severe relationship between poverty and disability in some counties. This means that poverty and disability affect one another in these counties. This relationship is likely to damage the disabled individuals and their families.

The findings of the present study indicate that no significant difference was observed between the counties in terms of most of the variables investigated. The findings of the present study are consistent with those of the studies conducted by Moss et al [4] and Islam [6] about the differences of different areas in terms of variables such as the disabled individuals' gender and spatial distribution. However, the findings of the present study are not consistent with those of the study conducted by Islam [6]; most of the disabled individuals are not rural residents. Since most of the disabled individuals of Khuzestan are urban residents. Moreover, the findings of the 
present study confirm those of the studies conducted by Goli et al [2] and Higgs et al [3]; it is of great significance to pay due attention to disability in its geographical background and adopt policies based on the geographical difference.

\section{Limitations}

A fundamental limitation of the study was the individuals cause and time of disability has not been registered. The availability of these data could have helped us to provide proper spatiotemporal analyses. Another limitation of this study is the lack of sufficient literature on the spatial analysis of disability variables. For this reason, comparing the similarities and differences was not completely conducted in the present study. In this study, disability was investigated in general. Thus, it is recommended to deal with the causes and times of disabilities in their geographical background in more details in the future studies.

\section{Conclusions}

According to the findings of the present study, most of the disabled individuals were urban residents. The physical disability was more frequent than other types of disabilities. In terms of disability rate, there is a significant difference between different counties. Most of the disabled individuals are suffering from severe and extremely severe disabilities, and there is a significant difference between different counties in terms of the severity of disability. Men and young individuals account for a large number of the disabled population. The number of married disabled individuals were more than that of the single disabled individuals. Most of the disabled individuals are illiterate or have elementary school or junior high school degrees. Most of the individuals are unemployed and occupational opportunities have not been created for them. Moreover, the findings of the study indicate that although there is a positive relationship between population and poverty with the disability rate, the significance of this relationship is different in different counties; one cannot generalize this relationship to all counties. In terms of disability variables, there is a significant difference between different counties. Thus, for reducing the ever-increasing problems of disabled individuals, it is of high significance to adopt different strategies corresponding to the regional features.

\section{Acknowledgments}

The author would like the Welfare Organization of Khuzestan Province for providing data and funding the research.

\section{Competing interests}

The authors remark that they have no financial or personal relationships that might have inappropriately influenced them writing this paper.

\section{Authors' contributions}

This section will be completed.

\section{Funding}

The Welfare Organization of Khuzestan Province funded the project. The funding body played no role on the study design, the writing of the paper or the decision to submit the manuscript for publication.

\section{References}

"ISC". Estimating the population of the country 2018 [cited 2018 Accessed on 24/02/2018. ]; Available from: https://www.amar.org.ir .(in Persian) (CrossRef)

Goli, A., F.S. Kermany, and M. Askarian, Spatial prevalence of intellectual disability and related socio-demographic factors in Iran, using GWR: case study (2006). International journal of preventive medicine, 2014. 5(3): p. 313.(PubMed)

Higgs, G., D.P. Smith, and M.I. Gould, Findings from a survey on GIS use in the UK National Health Service: organisational challenges and opportunities. Health Policy, 2005. 72(1): p. 105-117.doi: 105-117. 10.1016/j.healthpol.2004.06.011.(Google scholar)

Moss, M.P., M.C. Schell, and R.T. Goins, Using GIS in a first national mapping of functional disability among older American Indians and Alaska natives from the 2000 
DOI:

census. International journal of health geographics, 2006. 5(1): p. 37.doi: 10.1186/1476-072X-5-37 (PubMed)

Zheng, Y., et al., Mapping the neck disability index to $S F-6 D$ in patients with chronic neck pain. Health and quality of life outcomes, 2016. 14(1):

p.

21.https://doi.org/10.1186/s12955-016-0422-

x. (Google scholar)

Islam, M.M., An Analysis of Spatial Patterns of Disabled Persons in West Bengal. Indonesian Journal Of Disability Studies (IJDS), 2017. 4(2): p. 137-145.(Google scholar)

WOKP, Khuzestan disability data, W.O.o.K.P. "WOKP", Editor. 2017: Khuzestan Province.

Safety, $T$. The statistics of road accidents of the country from years 2011-2016. 2018 [cited 2018 Accessed on 09 January 2018. ]; Available from: http://transportsafety.ir.(in Persian)

Mennis, J., Mapping the results of geographically weighted regression. The Cartographic Journal, 2006. 43(2): p. 171-
179.doi/abs/10.1179/000870406X114658[ㅁo ogle Scholar] [CrossRef]

Fotheringham, A.S., M.E. Charlton, and C. Brunsdon, Geographically weighted regression: a natural evolution of the expansion method for spatial data analysis. Environment and planning A, 1998. 30(11): p. 1905-1927.doi:10.1068/a301905 [Google Scholar]

Braithwaite, J. and D. Mont, Disability and poverty: a survey of World Bank poverty assessments and implications. ALTEREuropean Journal of Disability Research/Revue Européenne de Recherche sur le Handicap, 2009. 3(3): p. 219-232.

Mitra, S., A. Posarac, and B. Vick, Disability and poverty in developing countries: $A$ snapshot from the World Health Survey. 2011: World Bank.[Google Scholar]

Maleki, S. and R. Ahmadi, Investigating The Impact Of Distance From Center On The Development Level of Khouzestan Cities. 2016. 